\title{
Patterns of Fungi Isolates from Sputum Samples of HIV Subjects Co-Infected with Pulmonary Tuberculosis in Eastern Nigeria
}

\author{
Vivian C. Onuoha, Ifeoma B. Enweani, Ogbonnia Ekuma-Okereke* \\ Department of Medical Laboratory Science, Nnmadi Azikiwe University, Nigeria \\ Received October 22, 2019; Revised December 25, 2019; Accepted December 30, 2019
}

Copyright $\mathrm{C} 2019$ by authors, all rights reserved. Authors agree that this article remains permanently open access under the terms of the Creative Commons Attribution License 4.0 International License

\begin{abstract}
Opportunistic infection in HIV positive individuals has a high risk of morbidity and mortality as it could be a pointer to systemic infection. Aim: This study was designed to determine the patterns of some pathogenic fungal infections isolated from HIV positive individuals from ART clinics in south eastern Nigeria. Materials and methods: A total of 132 patients (62 males and 70 females) were recruited for this study. Their sputum samples were screened for Tuberculosis (TB) using Ziehl Nelsen staining technique and were also cultured on Sabouaurd dextrose agar with and without chloramphenicol incubated at $25^{\circ} \mathrm{C}$ with examination of growth every 3 days for two weeks. Identification of isolates was done using Gram staining methods, chromogenic media and slide culture. Results: $46(34.8 \%)$ of the test subjects (132) were co-infected with TB while $94(71.2 \%)$ tested positive for fungi infection; $36(60.0 \%)$ for HIV-sero positive subjects on ART and $58(80.6 \%)$ for those not on ART $(\mathrm{P}<0.05)$. The prevalence of fungi isolates from test subjects shows that Candida albicans has the highest frequency of $25(26.6 \%)$, followed by Penicillum marneiffei with 18(21.6\%), with the least prevalent being Aspergillus flavus and Phialemonium curvatum at $2(2.1 \%)$ respectively. In HIV-sero negative indivuals, Candida albicans was of the highest prevalence with $7(53.9 \%)$, followed by Candida tropicalis with 3(23.1\%) and Aspergillus fumigatus and A. flavus with the least prevalence of $1(7.7 \%)$ respectively. Furthermore, there was a positive significant correlation between TB and fungi infection in $\mathrm{HIV}$-sero positive subjects $(\mathrm{P}<0.05)$. Conclusion: The high prevalence of fungi infection amongst TB co-infected HIV-sero positive individuals suggests a high degree of drug resistance in said patients thus, could be the mitigating factor behind the increasing morbidity and mortality among TB co-infected HIV positive subjects.
\end{abstract}

Keywords Human Immune Virus (HIV),
Tuberculosis, Fungi Isolates, Opportunistic Infections

\section{Introduction}

The Human Immune deficiency Virus (HIV) is a lentivirus (slowly replicating retrovirus) that causes Acquired Immuno Deficiency Syndrome (AIDS), a condition in humans in which progressive failure of the immune system allows life threatening opportunistic infections and cancers to thrive (Doueket. al., 2009). Its modes of transmission ranges from sexual intercourse with an infected partner (including anal, oral sex), sharing of an infected objects such as needles, razor, and syringes with an infected person, person to person through contaminated blood and other body fluids, and from mother to unborn child during pregnancy, delivery or breast-feeding, and through transfusion with an infected blood and blood products. HIV has been found in saliva and tears in low concentrations in some AIDS patients. However, contact with saliva, tears or sweat has shown to result in transmission (Moiret. al., 2005).

UNAIDS and WHO estimates that AIDS has killed more than 25 million people since it was first recognized in 1981 , making it one of the most destructive pandemics in recorded history (UNAIDS, 2009). Despite recent improved access to antiretroviral treatment and care in many regions of the world, the AIDS pandemic claimed an estimated 2.8million (between 2.4 and 3.3 million) lives in 2005 of which more than half a million $(570,000)$ were children. Sub -Saharan Africa remains by far the worst affected region with an estimated 21.6 to 27.4 million people currently living with HIV. About 2 million of them are children younger than 15 years of age (WHO, 2011). More than $64 \%$ of all people living with HIV are in 
Sub-Sahara Africa, as more than 3 quarters of all women living with HIV. In Nigeria, a prevalence rate of $3.1 \%$ has been reported (WHO, 2011).

HIV infects vital cells in the human immune system such as helper $\mathrm{T}$ cells (specifically, CD4 $+\mathrm{T}$ cells), macrophages, and dendritic cells (Cunningham, et al., 2010). HIV infection leads to low levels of CD4+ T cells through a number of apoptosis of uninfected by-stander cells, direct viral killing of infected cells and killing of CD4+ $\mathrm{T}$ cells by CD8 cytotoxic lymphocytes that recognize infected cells. When $\mathrm{CD} 4+\mathrm{T}$ cells numbers decline below critical level cell mediated immunity is lost, the body becomes progressively more susceptible to opportunistic fungal infections being the major cause of morbidity and mortality in these patients (Banerjee, 2005).

Fungi are widely distributed throughout the environment. The lungs are the common portal of entry for most fungi into the human host. Fungal infection is a predominant source of morbidity and mortality among HIV positive individuals in late stages of HIV infection and low CD4 counts below $500 \mathrm{cells} / \mu \mathrm{m}$, is opportunistic infection caused by agents that rarely infect immune competent individual (Jawetz, et al.,2007). The occurrence of opportunistic fungal infection has risen progressively in recent years. Invasive fungal infections has been reported in recent years in $26 \%$ of chronically and intensively immune suppressed patients (Topley and Wilson, 2005) as cited by (Bharathi and Usha, 2011). Infection with Candida albicans appears when CD4 counts is between 500-200 cells $/ \mu \mathrm{m}$ and may be the first indication of immunodeficiency. Cryptococcal infection occurs when CD4 count has fallen below 150 cells $/ \mu \mathrm{m}$. Penicillosis is observed in patients with CD4 counts of less than 100 cells $/ \mu \mathrm{m}$ (Guidelines for prevention and treatment of opportunistic infections in HIV infected Adults and Adolescent, 2009). HIV positive individuals are prone to get recurrent fungal infection due to damages on the cells that gives protection on humans, and therefore more vulnerable to develop pathogenic yeasts and mould infections. The pathogenic yeasts and moulds infections depend on the exposure to sufficient inoculum size of the organism and general resistance of the host.

Tuberculosis and HIV constitute the main burden of infectious disease in resource-limited countries. Estimates by the World Health Organization (WHO) indicate that there are more than 9 million new activate case of TB and close to 2 million death per year (WHO, 2012), and that 2.6 million new cases of HIV infection and 1.8 million AIDS related deaths occur per year (UNAIDS, 2010). Mycobaterium tuberculosis- HIV co-infections pose particular diagnosistic and therapeutic challenges and exert immense pressure on health care systems in Africa and Asian countries with large population of co-infected individuals.

In the individual host with the two pathogens, $M$. tuberculosis and HIV potentiate one another, accelerating the deterioration of immunological functions and resulting in premature death if untreated. Some 14 million individuals worldwide are estimated to be dually infected (Getahumet. al., 2010). TB is the largest single cause of death in the setting of AIDS, accounting for about $26 \%$ of AIDS related deaths (Getahumet. al., 2010). Both TB and HIV have profound effects on the immune system, as they are capable of disarming the hosts' immune responses through mechanisms that are not fully understood. HIV co-infection is the most powerful known risk factor for progression of Mycobacterium tuberculosis infection to active disease increasing the risk of latent TB reactivation 20-fold (Getahumet. al., 2010).

\subsection{Statement of Problem / Study Significance}

There has been an increase in the resistance of first line drugs used in the treatment of HIV patients co-infected with pulmonary tuberculosis thereby resulting to high morbidity and mortality of affected patients in developing countries, including Nigeria. It is documented that HIVsero positive individuals co-infected with tuberculosis are at greater risks of damaging effects of opportunistic infections due to their decreased immunity. Therefore, this study aims at evaluating prevalence of some pathogenic fungi which couild be the underlying factors to the increasing drug resistance in HIV-sero positive patients' co-infcted with pulmonary tuberculosis.

\subsection{Aim}

This study was designed to determine the patterns of some pathogenic fungal infections isolated from HIV positive individuals from ART clinics of Nnamdi Azikiwe University Teaching Hospital, Nnewi, Anambra State and Holy Rosary Hospital, Emekuku, Owerri, Imo State of South-Eastern Nigeria.

\section{Materials and Methods}

\subsection{Culture Media and Other Reagents}

These include Soxhlet extractor, methanol, n-hexane, ethyl acetate, butanol, and aqueous (water), Sabouraud Dextrose agar and Sabouraud Dextrose broth (Lab M, UK), Tween 80, Dimethyl sulfoxide (DMSO), etc.

\subsection{Equipment and Instruments}

These include Incubator (Genlab, UK), Autoclave (EQUITRON Partially Automatic Autoclave, by Medica Instrument Manufacturing Co., India), Hot Air Oven (Genlab, UK), Electronic weighing balance (Ohaus Corp., USA), etc. 


\subsection{Glass Wares and Other Materials}

These include Petri dishes, test tubes, McCartney and bijou bottles, beakers, conical flasks glass slide and coverslip, measuring cylinders, meter rule, funnels, syringes, micropipettes, etc.

\subsection{Study Location}

This study was carried out in Nnamdi Azikiwe University Teaching Hospital (NAUTH), Nnewi, Anambra State and Holy Rosary Hospital Emekuku, Owerri (HRH), Imo State all in Nigeria. It is the only mission hospital in Owerri that serves as a treatment centre for patients with both Mycobacterium tuberculosis and HIV/AIDS from Owerri and beyond. Nnewi is coordinated at $6^{0} 11^{\prime} \mathrm{N}$, $6^{0} 55^{\prime} \mathrm{E} / 6.017^{\circ} \mathrm{N}, 6.917^{\circ} \mathrm{E}$ of Nigeria comprising of both Nnewi North and North South with an estimated population of 391,227 according to the Nigeria census. The city spans over $1,076.9$ square miles $\left(2,789 \mathrm{~km}^{2}\right)$ in Anambra State. NAUTH is a tertiary health institution serving patients of high, middle and lower socio economic status and one of the Federal Teaching Hospital in the South Eastern Nigeria and the only one in the state. It houses major HIV/AIDS centre (IHVN Clinic) and Mycobaterium tuberculosis serving patients from all parts of the state and beyond.

\subsection{Study Population}

A total of 153 subjects comprising of 51 HIV-sero positive patients on ART, $51 \mathrm{HIV}$-sero positive subjects not on ART attending Out Patient Clinic at NAUTH, Nnewi and HRH Emekukwu, Owerri and 51 HIV-sero negative individuals.

\subsubsection{Inclusion Criteria}

This study includes HIV-sero positive patients on HAART, HIV-sero positive individuals not on HAART; HIV-sero positive patients co-infected with pulmonary tuberculosis as test subjects and HIV-sero negative patients serving as controls.

\subsubsection{Exclusion Criteria}

This study excluded patients that refused to give their consent.

\subsection{Ethical Approval}

Ethical clearance was sought for and obtained from the Ethics Committte of Nnamdi Azikiwe University Teaching Hospital, Nnewiand HRH Emekuku Ethical Committee in accordance with the code of ethics for biological research involving human subjects in order for this project to be carried out. Individual consent was also obtained from the patients after proper explanation to them concerning the work using a well-structured questionnaire.

\subsection{Data Collection}

Questionaries were distributed to the HIV positive and HIV negative individuals. Socio-demographic data and clinical records were collected for the mycological study.

\subsection{Sample Collection}

\subsubsection{Sputum for Acid Fast Bacilli (AFB)}

Three (3) early morning sputum samples were collected in 3 consecutive days from each of the HIV patients. Patients were asked to collect the sample in a sterile wide mouthed container. According to the methods described in (Chessbrough, 2006)

\subsubsection{Sputum for Culture}

A wide mouthed sterile labeled container was given tothe HIV positive and HIVnegative patients. Patients were asked to produce the sputum into the container.

\subsubsection{Blood}

Four (4ml) of blood was collected from each participants according to the methods described by Chessbrough, (2006) with EDTA container for HIV screeningand CD4 cell count. All aseptic conditions were observed accordingly.

\subsection{Analysis of Samples}

\subsubsection{Sputum Sample}

\subsubsection{Cultural Technique}

Each sputum sample were inoculated on two sets of Sabourand's dextrose agar (SDA) impregnated with antibiotic, chloramphenicol and SDA without antibiotic). Media plates were incubated at $25^{\circ} \mathrm{C}$ with examinations for growth on every three days for two weeks. SDA plates with growth were identified macroscopically and microscopically. Criteria for positive growth were based on two plates from the same patients yielding the same growth.

\subsubsection{Sabourand Dextrose Agar (SDA) Preparation}

Sabourand dextrose agar with actidion by microndia Trading Home, Torbagyi India.

Composition:

Peptone $10.0 \mathrm{~g}$

Agar $14.3 \mathrm{~g}$

Glucose $37.7 \mathrm{~g}$

Chloramphenicol $0.1 \mathrm{~g}$

Cycloheximide $0.5 \mathrm{~g}$

\section{Preparation:}

$62.6 \mathrm{~g}$ of the powder was weighed out and added to 1 liter of distilled water. It was allowed to soak for 10 minutes, swirled to mix then sterilized by autoclaving for 15 minutes at $121^{\circ} \mathrm{C}$, cooled at $47^{\circ} \mathrm{C}$ before pouring into 
petri dishes. This was allowed to gel.

\subsubsection{Gram Staining Technique}

Gram's staining was done to all the isolates with mucoid yeast-like growth and observed for gram positive budding yeast cells. (Chessbrough, 2006. Appendix V)

Reagents: Crystal violent, lugols iodine, acetone and neutral red.

Methods:

- A loopful of the culture was smeared on a greese free slide.

- The dried smear was heat-fixed.

- It was covered with crystal violet stain for 30-60 seconds.

- The stain was washed off with water.

- The smear was covered with lugols iodine for 30-60 seconds

- It was washed with water and then decolourized with acetone and washed immediately with water.

- The smear was covered with neutral red for 2 minutes and then washed off with water.

- It was dried and examined microscopically using 100X objectives for budded yeast cells.

\subsection{Identification of Fungal Isolates}

The different fungal isolates were identified macroscopically and microscopically by the methods described by Mackie McCantey, (2008).

\subsubsection{Macroscopic Identification}

This was based on the colonial morphology of the isolates appearing on the laboratory media. Visual examination was based on the physical appearance such as colour, texture, colonial topography and diffusible pigments.

Mucoiod yeast-like growth was processed by Gram staining and inoculation on CHROMagar Candida.

\subsubsection{Microscopic Identification}

The definitive identification was based on the morphology of the spores and hyphae on the preparation with lactophenol cotton blue (LCB) on wet mount technique. The morphological features were observed and identified. Chessbrough, 2006.

\subsection{Slide Culture Technique for Fungi}

Potato Dextrose Agar Preparations for slide culture

\section{Compositions}

Potato infusion from $200 \mathrm{~g} 4 \mathrm{~g}$

Dextrose 20g

Agar 15g

$4.0 \mathrm{~g}$ of potato extract is equivalent to $200 \mathrm{~g}$ of infusion from potatoes. Final pH $5.6 \pm 0.2$ at $25^{\circ} \mathrm{C}$.

\section{Principles}

PDA is composed of dehydrated potato infusion and dextrose that encourages luxuriant fungal growth. Agar is added as the solidifying agent. Many standard procedures use a specified amount of sterile tartaric acid (10\%) to lower the $\mathrm{pH}$ of this medium to $3.5 \pm 0.1$, inhibiting bacterial growth. Do not reheat the acidified medium; heating in the acid state will hydrolyze the agar.

\section{Preparations}

- $\quad$ Suspend $39 \mathrm{~g}$ of the medium in $1 \mathrm{~L}$ of purified water.

- Heat with frequent agitation and boil for 1 minute to completely dissolve the medium.

- Autoclave at $121^{\circ} \mathrm{C}$ for 15 minutes and poured into petri dishes and allowed to solidify to gel.

\subsubsection{Identification of Candida Species}

Candida species were identified on a selective and differential medium known as CHROMagar Candida.

Procedure:

- A litre $(1000 \mathrm{ml})$ of water was autoclaved.

- $\quad 33 \mathrm{~g}$ of the CHROMagar Candida powder was dissolved in it.

- It was heated on a bunsen flame until complete dissolution of the agar.

- It was poured into the petri-dishes and allowed to solidify.

- The Candida isolated were cultured on it and then incubated for upto $48 \mathrm{hrs}$

- The Candida species were identified based on their chromogenic reaction.

\subsubsection{Identification of Candida Species with CHROMagar Candida}

Different Candida species were identified on a selective and differential chromogenic media (CHROMagar Candida). The Candida CHROMagar was prepared according to manufacturer's instructions. The Candida species were identified based on their chromogenic reaction as described in the instruction by the manufacture's instruction. Candida albicans (green), Candida tropicalis (blue), Candida glabrata (pink), and Candida krusie (dry pink).

\subsubsection{Identification of the Growth Appearance with Slide Culture}

The fungal isolates were cultured onto potato dextrose agar for slide culture. This helps in the microscopic examination of the features of fungi on which classification depends on the spores and the spore-bearing apparatus. Riddels initiates slide culture in order to accurately identify many fungi by the arrangement of their conidiophores and the way in which spores are produced (condial ontogeny). 


\section{Procedure for slide culture}

1. Complete identification of molds is often dependent upon observation of the undisturbed relationship of the sporulation structures.

2. Using aseptic technique cut a prepared plate of Potato Dextrose Agar in sections approximately $1 \mathrm{~cm}$ square and 2-3 $\mathrm{mm}$ deep.

3. Place a bent glass rod in a petri dish and balance a sterile glass slide on top.

4. Place one block of agar on the center of the slide.

5. Inoculate each of the four sides of the block with the fungi for study. Cover with a sterile coverslip.

6. Add 6-8 $\mathrm{ml}$ of sterile water to the bottom of the dish to maintain a moist environment.

7. Incubate at room temperature $25^{\circ} \mathrm{C}$ until sporulation occurs.

8. Place a drop of Lacto-phenol cotton-blue on end of a second glass slide. Gently lift coverslip and place on the drop.

9. Discard agar block. Place drop of Lacto-phenol cotton-blue in the center of the growth area and cover with a second coverslip.

10. Blot excess fluid and seal edges with fingernail polish or appropriate varnish.

11. Examine microscopically and use atlas to confirm each arrangement.

\subsection{HIV Screening}

HIV screening was done using Determine HIV-1/2 test kit, Uni-Gold kit (Trinity Biotech) and STAT-PAK (Chembio Diagnostic System, Inc.) was used for the HIV screening.

Principle:

It is based on immune-chromatographic sandwich principle. Algorithm is defined as combination and sequence of specific tests in a given testing strategy. A HIV positive status should be based upon the outcome of two or more tests. Serial testing means sample tested by first test kit, with the results of the first test determining whether additional testing is required. If the first kit shows non-reactive; the sample will be reported as HIV negative. If the first kit shows a reactive result, sample will be further tested by the second test kit; if the second test kit shows a reactive result, the tested sample will be reported as HIV positive. When the two test results disagree (the first is reactive and the second is non-reactive), a third test will be performed with the result of third test serving as the final result.

\subsection{Cyflow Counter for Automated Cd4+ T Cell Count}

\section{Principle}

The calibration is based on the use of count check beads to verify counting cycle, signal position on the scale and peak or signal characteristics. The stained CD4+ Tcell is energized by the application of the laser beam, which invariably interpret, and present CD4+ Tcells on liquid crystal display (LCD) screen as peaks.

\section{Procedure}

$20 \mu 1$ of EDTA whole blood will be collected into partec test tube (Rohren tube). The $20 \mu 1$ of CD4+ Tcell antibody will be added into the tube. The content will be mixed and incubated in the dark for 15 minutes at room temperature. $800 \mu 1$ of CD4 buffer will be gently added into the mixture and mix gently. The partec tube will be plugged on cyflow counter and the $\mathrm{CD} 4+\mathrm{T}$ cells will be displayed as peak and interpreted as figures.

\subsection{Statistical Analysis}

Statistical analysis was done using chi-square and correlation set as $95 \%$ confidence limit and 0.05 level of significance respectively. Statistical package for socio science version 17 was used for the evaluation.

\section{Results}

\subsection{TB and Fungi Infection Status of HIV-sero Positive Subjects on ART and Those Not on ART}

Out of the 132 HIV-sero positive subjects sampled, 60 patients were on antiretroviral drugs while 72 were not on ART. 16 out of the 60 subjects on ART were TB positive while 30 out of the 72 subjects not on ART were TB positive. More so, 36(60.0\%) individuals on ART were positive for fungi infection while $58(80.0 \%)$ of subjects not on ART were positive for fungi infection $(\mathrm{P}<0.05)$ respectively.

Table 1. TB and fungi infection status of HIV-sero positive subjects on ART and those not on ART

\begin{tabular}{|c|c|c|c|c|c|}
\hline $\begin{array}{c}\text { Status of HIV Positive } \\
\text { Subjects }\end{array}$ & $\begin{array}{c}\text { ART status of test } \\
\text { subjects }\end{array}$ & $\begin{array}{c}\text { TB status of } \\
\text { test subjects }\end{array}$ & $\begin{array}{c}\text { Fungi status of test } \\
\text { subjects }\end{array}$ & $\mathbf{X}^{2}$-value & p-value \\
\hline On ART & 60 & 16 & $36(60.0)$ & & \\
\hline Not on ART & 72 & 30 & $58(80.6)$ & & \\
\hline Total & $\mathbf{1 3 2}$ & $\mathbf{4 6}$ & $\mathbf{9 4 ( 7 1 . 2 )}$ & $\mathbf{2 5 . 3 0}$ & $\mathbf{0 . 0 0 0 *}$ \\
\hline
\end{tabular}

Keys \%:=Percentage, No: =Number, $\mathrm{X}^{2}:=$ Chi-square, $*:=$ significant, TB: =Tuberculosis, Pts:=Patients.

NB: $\mathrm{P}<0.05=$ significant, $\mathrm{P}>0.05=$ not significant 


\subsection{Prevalence of Single Fungal Isolates from Sputum Samples of HIV-sero Positive and Sero Negative Individuals}

Table 2 shows the frequency of the different single fungal isolates from the sputum samples of HIV-sero positive and negative individuals. A total of 8 different fungi were isolated comprising of Candida albicans with the highest frequency of fungi isolates amongst test subjects $25(26.6 \%)$, followed by Penicillum marneiffei with 18(21.6\%), followed by Candida tropicalis with 13(13.8\%), followed by Aspergillus fumigatus with 5(5.3\%), followed by Aspergillus niger with 3(3.2\%), followed by Aspergillus flavus and Phialemonium curvatum with same prevalence of 2(2.1\%) respectively. However, among the HIV sero-negative indivuals, Candida albicans was of the highest prevalence with 7(53.9\%), followed by Candida tropicalis with 3(23.1\%) and Aspergillus fumigatus and A. flavus with the least prevalence of $1(7.7 \%)$ respectively.

Table 2. Prevalence of single fungal isolates from sputum samples of HIV-sero positive and sero negative individuals

\begin{tabular}{|c|c|c|}
\hline Fungi Isolates (Single) & $\begin{array}{c}\text { No(\%) of isolates } \\
\text { from HIV } \\
\text { positive subjects }\end{array}$ & $\begin{array}{c}\text { No(\%) of isolates } \\
\text { from HIV } \\
\text { negative sunjects }\end{array}$ \\
\hline Candida albicans & $25(26.6)$ & $7(53.9)$ \\
\hline Penicillummarneiffei & $16(17.0)$ & $0(0.0)$ \\
\hline Candida tropicalis & $13(13.8)$ & $3(23.1)$ \\
\hline Candida krusei & $8(8.5)$ & $0(0.0)$ \\
\hline Aspergillusfumigatus & $5(5.3)$ & $1(7.7)$ \\
\hline Aspergillusniger & $3(3.2)$ & $0(0.0)$ \\
\hline Aspergillusflavus & $2(2.1)$ & $1(7.7)$ \\
\hline Phialemoniumcurvatum & $2(2.1)$ & $0(0.0)$ \\
\hline Total & $\mathbf{7 4 ( 7 8 . 6 )}$ & $\mathbf{1 2 ( 6 2 . 4 )}$ \\
\hline
\end{tabular}

$\mathrm{X}^{2}=0.06, \mathrm{P}=1.00 \mathrm{X}^{2}=0.23 \mathrm{P}=0.672$

\subsection{Prevalence of Mixed Fungal Isolates from Sputum Samples of HIV-sero Positive and Sero Negative Individuals}

Table 3 shows the mixed fungi infection isolated from both HIV-sero positive and negative subjects with Candida albicans and $P$. marneiffei occurring highest with 11(11.7\%), followed P. marneiffei and A. niger with a prevalence of 3(3.2\%) and C. albicans, A.flavus and $P$. marneiffei occurring least with a prevalence of $1(1.1 \%)$ in test individuals respectively. In HIV-sero negative subjects, C. albicans and A. fumigatus was only the mixed fungi isolate recoreded with prevalence if $1(7.7 \%)$.

Table 3. Prevalence of mixed fungal isolates from sputum samples of HIV-sero positive and sero negative individuals

\begin{tabular}{|c|c|c|}
\hline $\begin{array}{c}\text { Fungi Isolates } \\
\text { (Mixed) }\end{array}$ & $\begin{array}{c}\text { No / \% of isolates } \\
\text { from HIV positive } \\
\text { subjects }\end{array}$ & $\begin{array}{c}\text { No / \% of isolates } \\
\text { from HIV negative } \\
\text { sunjects }\end{array}$ \\
\hline $\begin{array}{c}\text { C. albicans and } P . \\
\text { marneiffei }\end{array}$ & $11(11.7)$ & $0(0.0)$ \\
\hline $\begin{array}{c}\text { P. marneiffei and } \\
\text { A. niger }\end{array}$ & $3(3.2)$ & $0(0.0)$ \\
\hline $\begin{array}{c}\text { C. tropicalis and } A . \\
\text { fumigatus }\end{array}$ & $2(2.1)$ & $0(0.0)$ \\
\hline $\begin{array}{c}\text { C. albicansand } A . \\
\text { niger }\end{array}$ & $2(2.1)$ & $0(0.0)$ \\
\hline $\begin{array}{c}\text { C. albicans and } A . \\
\text { fumigatus }\end{array}$ & $1(1.1)$ & $1(7.7)$ \\
\hline $\begin{array}{c}\text { C. albicans } \\
\text { A.flavus and } P . \\
\text { marneiffei }\end{array}$ & $1(1.1)$ & $0(0.0)$ \\
\hline Total & $\mathbf{2 0 ( 2 1 . 3 )}$ & $\mathbf{1 ( 7 . 7 )}$ \\
\hline
\end{tabular}

$\mathrm{X}^{2}=3.85,(\mathrm{P}=0.277)$

Keys: $\%=$ Percentage, $\mathrm{No}=$ Number, $\mathrm{X}^{2}=$ Chi square

\subsection{Prevalence of Fungi Infection amongst HIV-sero Positive and Negative Individuals in Relation to Their CD4 Count}

Table 4 shows the prevalence of fungi infection amongst HIV-sero positive and negative subjects in relation to their CD4 counts. Patients with CD4 count $<350$ cells $/ \mu$ l has the highest frequency of fungi infection with $34(97.1 \%)$, followed by those with CD4 count value between $351-500 \mathrm{cells} / \mu \mathrm{l}$ with a prevalence rate of $6(31.6 \%)$ whereas those with CD4 count $>500$ cells $/ \mu 1$ had no fungi infection isolated in HIV-sero positive subjects. However in control subjects (HIV-sero negative subjects), the highest prevalelence of fungi infection was recorded in subjects with CD4 count between $501-800 \mathrm{cells} / \mu 1$ with $12(27.9 \%)$, followed by those with CD4 count $801-1000 \mathrm{cells} / \mu 1$ with $1(5.0 \%)$ respectively.

Table 4. Prevalence of fungi infection amongst HIV-sero positive and negative individuals in relation to their CD4 count

\begin{tabular}{|c|c|c|c|c|}
\hline \multirow{2}{*}{$\begin{array}{c}\text { CD4 Count } \\
\text { Cells } / \mu 1\end{array}$} & \multicolumn{2}{|c|}{ HIV-Seo Positive Subjects } & \multicolumn{2}{c|}{ HIV-Seo Negative Subjects } \\
\cline { 2 - 4 } & No tested & No (\%) of fingi infection & No tested & No (\%) of fungi infection \\
\hline$<350$ & 112 & $88(78.6)$ & 0 & $0(0.0)$ \\
\hline $350-500$ & 19 & $6(31.6)$ & 43 & $0(0.0)$ \\
\hline $501-800$ & 0 & $0(0.0)$ & 20 & $12(27.9)$ \\
\hline $801-1000$ & 0 & $0(0.0)$ & 5 & $1(5.0)$ \\
\hline$>1000$ & 0 & $0(0.0)$ & 68 & $0(0.0)$ \\
\hline Total & 132 & $94(71.2)$ & & $13(19.1)$ \\
\hline
\end{tabular}

$\mathrm{X}^{2}=0.00,(\mathrm{P}=1.000)$

Level of significance $(\mathrm{P}>0.05)$ not significant

Key: $\%=$ Percentage, $\mu \mathrm{l}=$ Micro litre, $\mathrm{X}^{2}=$ Chi-square, $\mathrm{X}^{2}=0.667(\mathrm{P}=0.955)$

Level of significance $(\mathrm{P}>0.05)$ is not significant 


\subsection{Correlation Coefficient of TB, CD4 Count and Fungi Infection among HIV-sero Positive Subjects}

Table 5 shows the correlation coefficient of the different parameters studied in relation to the fungal infection. There was a positive significant correlation between TB and fungi infection in HIV-sero positive subjects $(\mathrm{P}<0.05)$ while CD4 count and fungal infection showed a non-significant negative correlation $(\mathrm{P}>0.05)$.

Table 5. Correlation coefficient of TB, CD4 count and fungi infection among HIV-sero positive subjects

\begin{tabular}{|c|c|c|}
\hline Parameters & $\begin{array}{c}\text { Correlation coefficient } \\
(\mathbf{r})\end{array}$ & P-value \\
\hline TB Vs Fungal infection & 0.813 & 0.002 \\
\hline $\begin{array}{c}\text { CD4 count Vs Fungal } \\
\text { infection }\end{array}$ & -0.210 & 0.720 \\
\hline
\end{tabular}

\section{Discussion}

Tuberculosis is a disease associated with immune compromised state while HIV has also been known to be associated with a depressed immunity. Tuberculosis and HIV co-infection pose particular diagnostic and therapeutic challenges. Infections with HIV are the most powerful known risk factor predisposing for Mycobacterium tuberculosis. Results obtained showed that out of a total of 132 HIV positive individuals between 11-80 years screened for Mycobacterium tuberculosis, 16(12.1\%) had Mycobacterium tuberculosis consisting of 5 males and 11 females with $(\mathrm{P}<0.05)$ showing that it is statistically significant in the study group. Out of the 68 HIV negative individuals with age range of $1-80$ years screened for Mycobacterium tuberculosis 5(7.4\%) had Mycobacterium tuberculosis consisting of 2 males and 3 females with $(\mathrm{P}>0.05)$ showing that there is no statistical significant relationship between tuberculosis and HIV negative individuals in the study group. The correlation analysis between the HIV positive co-infected with tuberculosis and HIV negative infected with tuberculosis and the prevalence of fungal infection is statistically significant at $(\mathrm{P}<0.05)$ meaning there is a positive association. Previous studies have shown that tuberculosis is the most common opportunistic infection in HIV positive patients particularly those with CD4 counts less than 200cells / $\mu 1$. Karim et al., (2009) in his study on Mycobacterium tuberculosis spoligotypes from tuberculosis patients in South Western Uganda reported a high prevalence of TB-HIV co-infection reaching up to $65 \%$ of the study population which is not in accordance with the present study. There is a high prevalence of fungal infection among HIV positive patients (71.2\%) unlike the HIV negative subjects $(19.1 \%)$ in the study. Esebelahie et al., (2013) reported a prevalence rate of fungal infection as $(52.5 \%)$ in HIV patients and $(30.0 \%)$ in HIV negative individuals which is contrary to the present study. Out of the 132 sputum samples of HIV positive patients cultured in the study,74(56.1\%) samples yielded single fungal isolates, mixed fungal isolates were observed in $20(15.2 \%)$ and the rest of the $38(28.8 \%)$ yielded no fungal growth. Out of the 74 single isolates, 8 different fungal species were obtained which includes Candida albicans 25(26.6\%), Penicillum marneffei 16(17.0\%), Candida tropicalis 13(13.8\%), Candida krusei 8(8.5\%), Aspergillus fumigatus 5(5.3\%), Aspergillus niger 3(3.2\%), Aspergillus flavus and Phialemonium curvatum 2(2.1\%) each. Mixed fungal isolates obtained includes Candida albicans and Pencillum marneffei 11(11.7\%), Candida albican and Aspergillus fumigatus 1(1.1\%), Aspergillus fumigatus and Candida tropicalis 1(1.1\%), Candida albican and Candida tropicalis 1(1.1\%), Penicllum marneffei, Aspergillus flavus and Candida albican 1(1.1\%). This study is contrary to the work of Bharathi and Usha- Rani, (2011) who sampled 100 sputum samples, 54 samples yielded single fungal isolates, mixed fungal isolates were observed in 20 samples and the rest 26 samples were no fungal growth. He also had Candida albicans in 42, Cryptococcus neoformans 4, Penicillum sp. Aspergillus fumigatus and Aspergillus niger 2 each, with Scedosporium apiospermum, Cunninghamella bertholletiae, Sporothix schenckii etc.This is in support of the present study which had Candida albicans as the predominant specie. Out of the 68 sputum samples of HIV negative individuals cultured in the study, $12(17.7 \%)$ samples yielded single fungal isolates, mixed fungal isolate $1(1.5 \%)$ was observed and no fungal growth was observed in $55(80.1 \%)$ sputum samples. Of the 12 single isolates, 4 different fungal species were obtained which included Candida albicans 7(53.9\%), Candida tropicalis 3(23.1\%), Aspergillus fumigatus 1(7.7\%), Aspergillus flavus 1(7.7\%) while the mixed fungal isolates include Candida albicans and Aspergillus fumigatus $1(7.7 \%)$. This is contrary to the findings of Esebelahie et al., (2014) whom isolated only 4 Candida albicans from 100 urine samples of HIV negative individuals. Also this study varies from the findings of Esebelahie et al., (2013) who reported 3 Candida species as Candida albicans, Candida krusei and Candida glabrata from non HIV individuals. The number of opportunistic fungal infections has increased in general among HIV positive patients $(71.2 \%)$ than HIV negative individuals (19.1\%) from this study. Candidiasis from this study was found to be the most common fungal infection in HIV/AIDS patients $25(26.6 \%)$ and 7(53.9\%) in HIV negative individual and is of prognostic value only as its presence indicates progression of immunodeficiency (WHO, 2011).This is contrary to the findings of This study is contrary to the findings of Bharanti et. al., (2010), in their study on the incidence of bacterial and fungal co-infection in some HIV infected Indian population reported a total of 6 different fungal isolates from sputum sample of which Candida albicans predominated. They also reported non- Candida species of which Candida tropicalis and Candida krusei was among. Esebelahie et al., (2013) in her study isolated 5 different Candida species; C.albicans was the most prevalent followed by C. krusei 
and C. parapsilosis while C.tropicalis and C.glabrata were the least prevalent recovered only from stool specimen. They also reported that Candida albicans was the most predominant specie recovered irrespective of their HIV status and the type of specimen processed. From their study also C. albicans were the most prevalent specie isolated irrespective of their HIV status. This varies from the present study in that 3 species of Candida were isolated from sputum specimen. Esebelahie et al., (2014) reported the prevalent of C. albicans $88.5 \%, C$. krusei $8.57 \%$ and $C$. parapilosis $2.86 \%$. This varies with the species isolated in this present studyas $C$. albicans predominates at $26.6 \%$, C.krusei $8.5 \%$ and C. tropicalis $13.8 \%$.

Penicillum marneffei was the second most common fungi isolated in the present study. It had a total of 18 samples (19.1\%) single isolates and 1 mixed isolates with Candida albicans and Aspergillus flavus (1.1\%). Penicillosis after tuberculosis and cryptococcosis is the third common opportunistic infection in patients with AIDS (WHO, 2011). It is always associated with low CD4 count typically less than 100 cells/ $\mu 1$ (WHO, 2009). It is very pathogenic and can mimic tuberculosis with $50 \%$ cases resulting to cough, dyspnea and hemoptysis. Bharanthi and Usha- Rani, (2011) in their study of pathogenic fungal isolates in sputum of HIV positive patients in India had 2 isolates out of the 100 sputum samples. Ranjana et al., 2002 reported 50 cases of disseminated Penicillum marneffei infection in HIV infected patients in Manipur State, India, this is contrary to the present study. Gupta et al., 2007 from New Delhi isolated Penicillum marneffei from HIV positive patients whose CD4 count were less than 100 cell $/ \mu 1$. Bharathiet al., (2010) Thanjavur, India isolated the samein one case of HIV positive patient. The finding from this study was in line with other study studies where P.marneffei occurs at CD4 count less than 100 cell $/ \mu 1$. Penicillum marneffei has been noted as a very important emerging systemic fungal infection in immune suppressed individuals especially in HIV patients

The next common isolate was Aspergillus species. Three different Aspergillus species were isolated which include Aspergillus fumigatus 5(5.3\%), Aspergillus niger 3(3.2\%), Aspergillus flavus 2(2.1\%) from HIV positive patient while 2 species were found from HIV negative individuals namely Aspergillus fumigatus 1(7.7\%) and Aspergillus flavus $1(7.7 \%)$. Aspergillosis exposure is universal though invasive aspergillosis is uncommon except in compromised cases like HIV infection (WHO, 2011). Bharathi et al., (2010) in their study on the incidence of bacterial and fungal co-infection in some HIV infected Indian population reported 7 cases of Aspergillus niger in 2011. Bharathi and Usha- Rani, (2010) reported 13 samples (13.5\%) of Aspergillus species with Aspergillus fumigatus and Aspergillus niger each 6 samples and Aspergillus flavus from 1 sample. These are synonymous to the findings of the present study.

This study also revealed that there is no statistical significant relationship between the male and female both in HIV positive and HIV negative individuals $(\mathrm{P}>0.05)$. This implies that fungal infection can infect individuals irrespective of gender. The prevalence was found to be higher in HIV positive individuals 94 (consisting of 48 females and 46 males) than HIV negative individuals 13 (consisting of 8 females and 5 males) in the present study. The correlation analysis between gender and prevalence of fungal infection was found to be statistically significant $(\mathrm{P}<0.05)$ for both HIV positive and HIV negative individuals. This is synonymous with the findings of Esebelahie et al., (2014) whom reported in his study that the prevalence rate of Candiduria was higher in females than in males.

The study shows that there is a statistical significance $(\mathrm{P}<0.05)$ between the marital status and the nature of occupation and fungal opportunistic infection in HIV positive patients implying the marital status or the nature of occupation is a predisposing factor for the prevalence of HIV infected subjects. This can be seen that traders had more fungi infection $36(78.3 \%)$, followed by artisans $17(70.8 \%)$, students $15(75.0 \%)$, farmers $12(70.6 \%)$, civil servants $9(64.2 \%)$, with the least among housewife $5(45.5 \%)$. In the HIV negative individuals there is no statistical significance $(\mathrm{P}>0.05)$ between marital status as well as occupation and the rate of fungal infection. This implies that marital status or the nature of occupation is not a predisposing factor for the prevalence of fungal infection in HIV negative subjects in the study.

The study also revealed that there is a statistical significant difference between the prevalence of opportunistic fungal infection among those on antiretroviral therapy $(\mathrm{ART})(\mathrm{P}<0.05)$. This shows that those not on ART are more infected with opportunistic fungal infection than those that are on ART. This could be attributed to the fact that ART reduces the chances of opportunistic infection by reducing the viral load and boosting the immune system of the HIV positive subjects. Also this is synonymous with the findings of Esebelahie et al., (2014) that Candiduria was associated with HAART naïve HIV patients with CD4 T cell counts $<200$ cells $/ \mu 1$. He also reported that a fungal agent such as Candida takes advantage of immune suppression seen in HIV patients as a result of CD4 $\mathrm{T}$ cell depletion. It also reported that HAART causes a decline in the incidence of some opportunistic infection in AIDS due to the restoration of immunity. This is in line with the present study which observed that fungal infection was higher among patients not on HAART than on HAART.

The correlation analysis between age and the prevalence of fungal infection was found to be statistically significant $(\mathrm{P}<0.05)$ for both HIV positive and HIV negative individuals. This could be observed that the rate of fungal infection was highest among 31-40 years in males and 21-30 in females which are believed to be the peak of the reproductive age which is associated with high sexual activity which is contrary to the finds of Eseblahie et al., 
(2013) whom reported that the highest prevalence was among the age range 61-70 years.

The correlation analysis between CD4 counts and prevalence of fungal infection was not statistically significant $(\mathrm{P}>0.05)$ meaning there is negative association between $\mathrm{CD} 4$ count and the rate of fungal infection indicating that as CD4 count increases the rate of fungal infection decreases. No wonder that there was no Penicillummarneffei isolated among the HIV negative individuals in the study. These findings also concur with the study of Bharathi et al., (2010) in India who reported that HIV positive with low CD4 counts had a higher prevalence of fungal infection. WHO (2011) in the manual for diagnosis of fungal opportunistic infection in HIV/AIDS patients recorded that people with low CD4 counts usually develop more fungal opportunistic infection.

\section{Conclusions}

The high prevalence of fungi infection amongst TB co-infected HIV-sero positive individuals suggests a high degree of drug resistance in said patients thus, could be the mitigating factor behind the increasing morbidity and mortality among TB co-infected HIV positive subjects.

It is recommended that the is screening of both HIV positive and HIV negative patients with or without cough symptoms for fungal pathogens in addition to bacterial pathogens as early diagnosis and treatment reduces further complications.

\section{Appendices}

\section{Bar Chart Representation of the Prevalence Rates of Fungi}

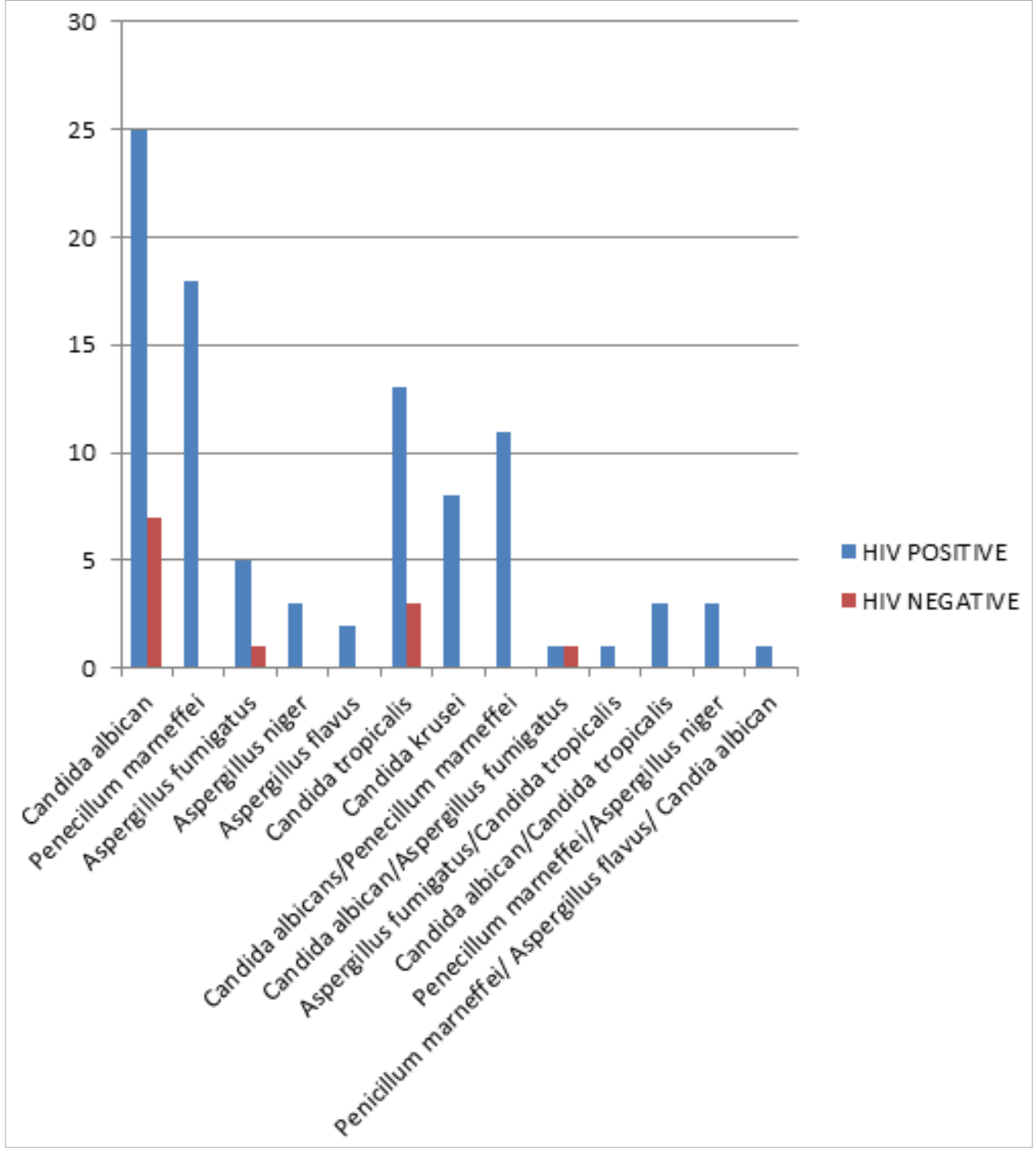




\section{Culture Plates of Isolates}
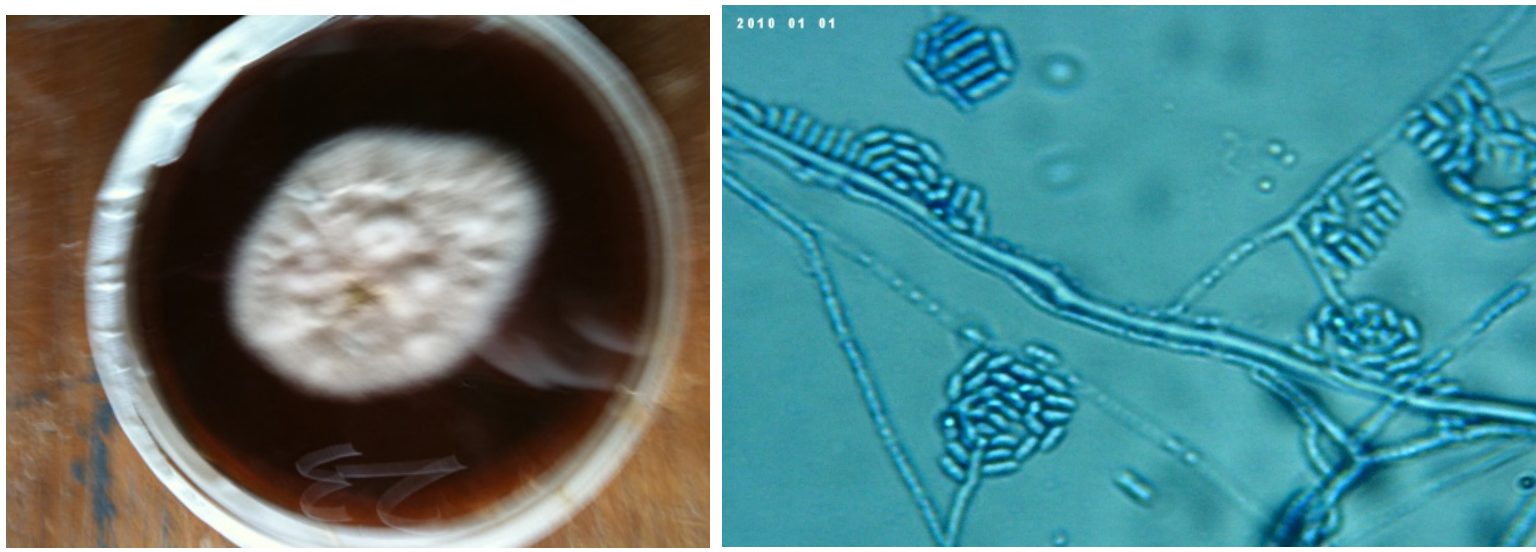

Plate 1. Phialemoniumcurvatum growth on SDA and Slide culture

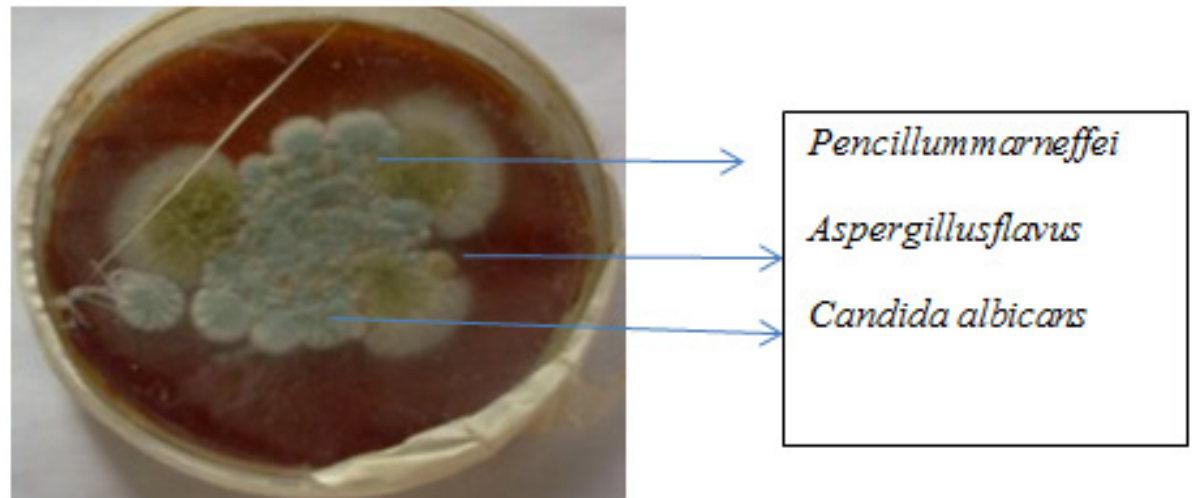

Plate 2. Penicillummarneiffei, Aspergillusflavus, and Candida albicanson SDA

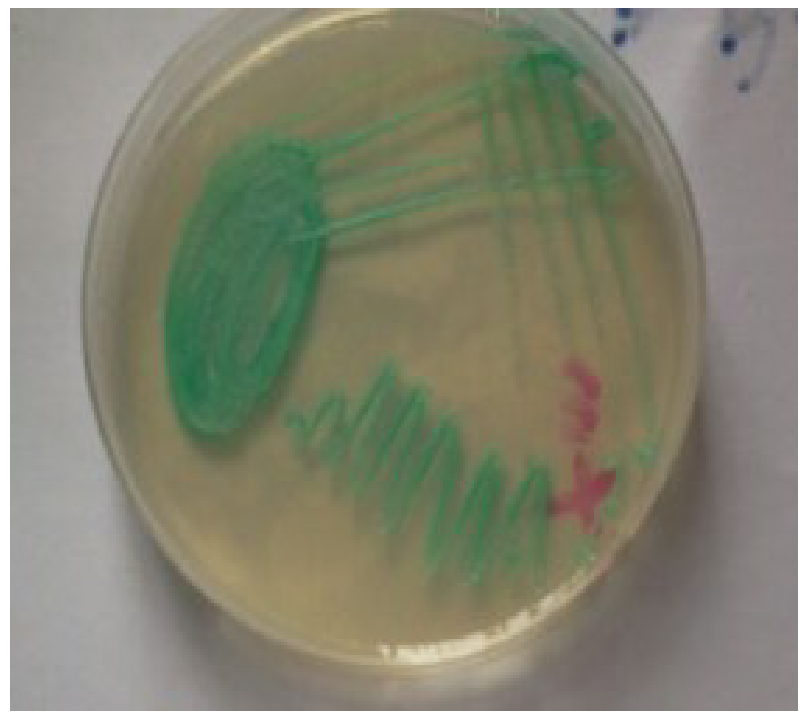

Plate 3. Candida albicans on CHROMagarCanidida 


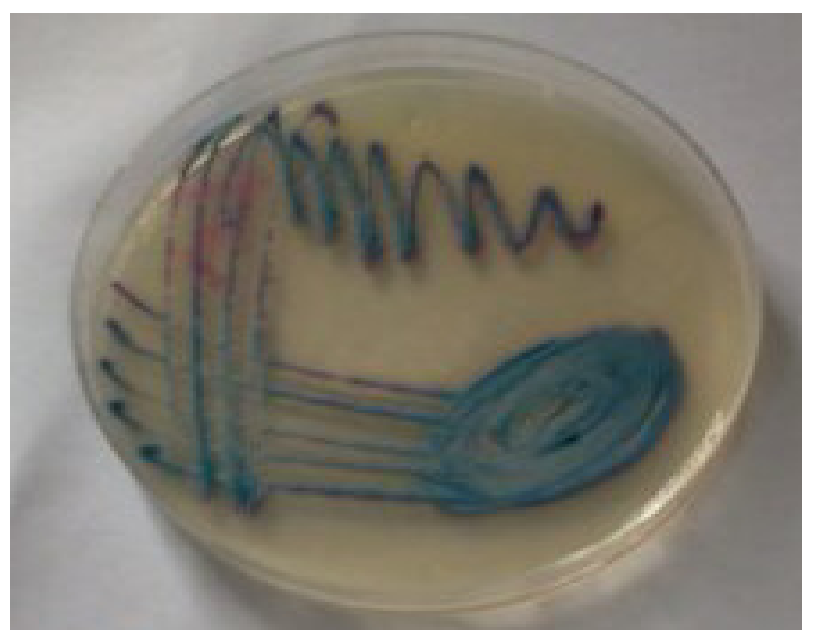

Plate 4. Candida tropicalis on CHROMagar Candida

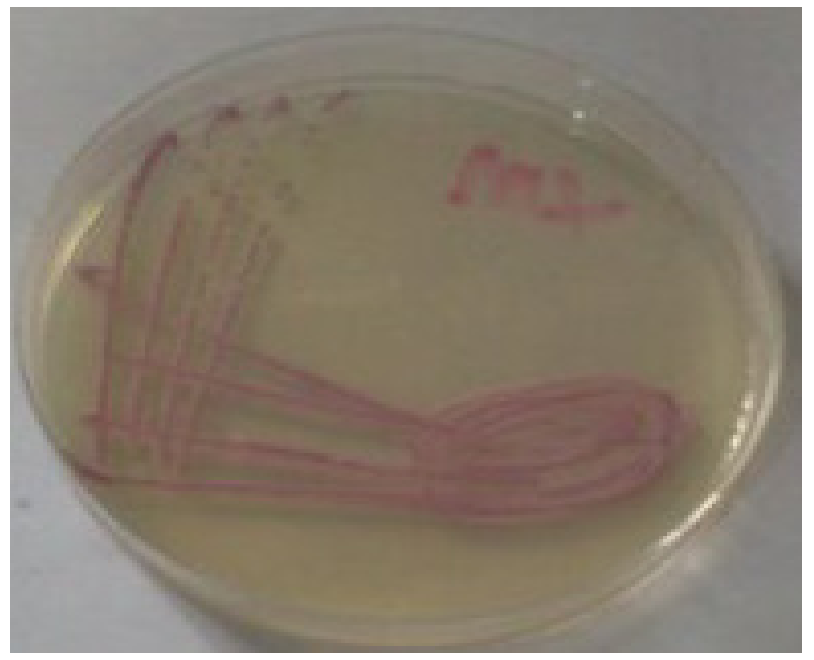

Plate 5. Candida krusei on CHROMagar Candida

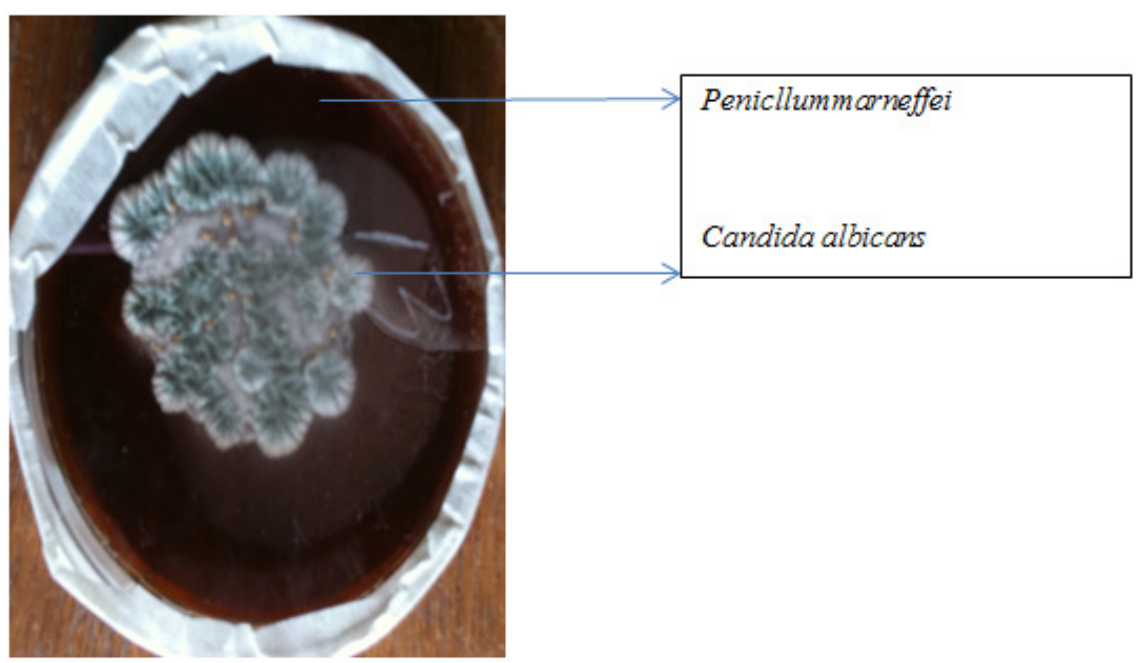

Plate 6. Penicillummarneiffei and Candida albicans growth on SDA 

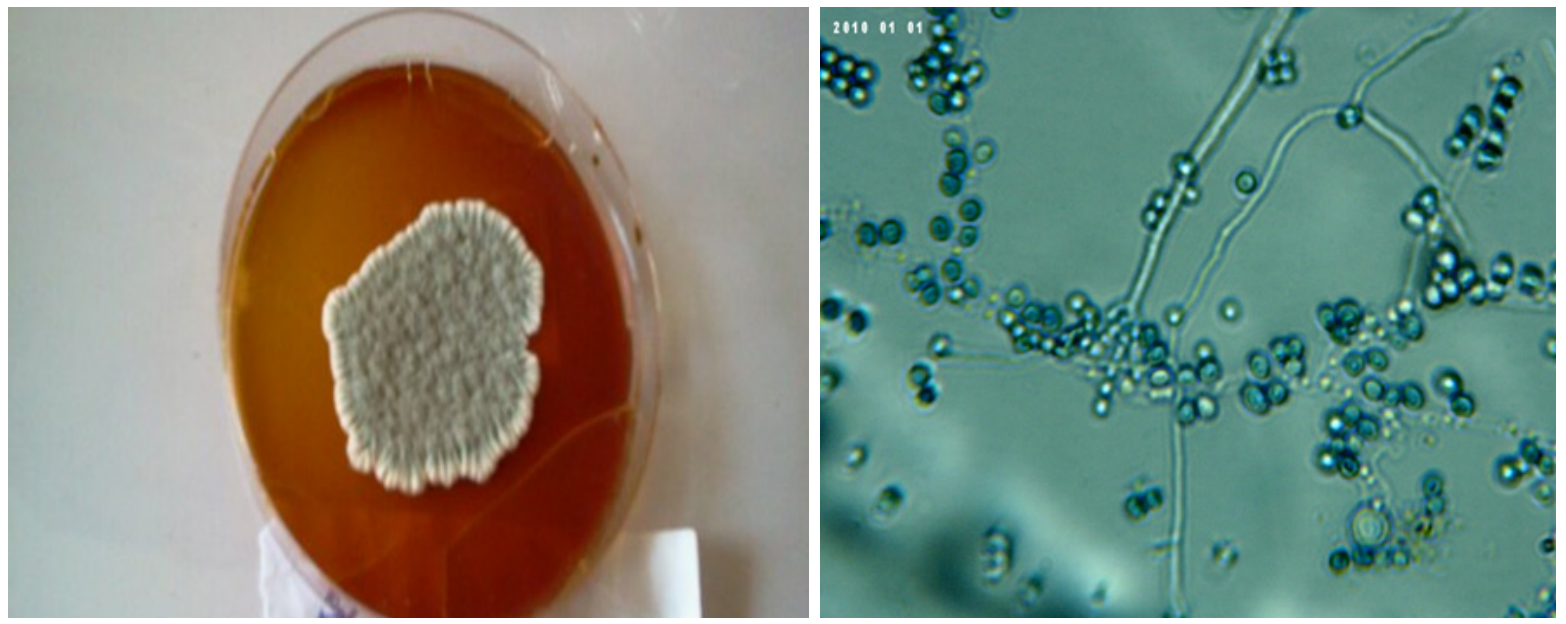

Plate 7. Penicillummarneffei on growth SDA and slide culture
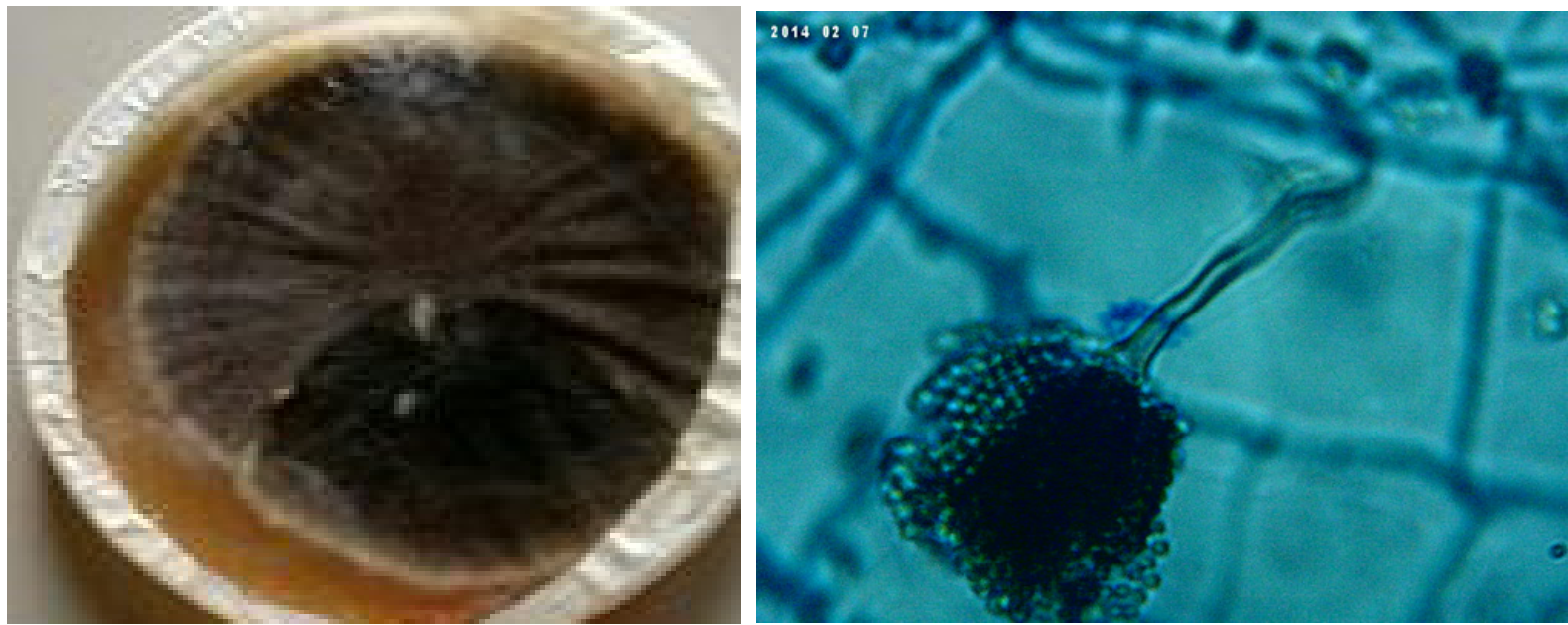

Plate 8. Aspergillusfumigatus on growth SDA and slide culture

$$
\text { 12(4):395-406. }
$$

\section{REFERENCES}

[1] Douek, D.C., Roederer, M., Koup, R.A. Emerging concepts in the immunopathogenesis of AIDS. Annual revolution medicine; 2009, 60:471-484.

[2] Moir, S., Chun, T.W., and Fauci, A.S. Pathogenic mechanisms of HIV disease. Annual Review on Pathology; 2011, 6: 223-248.

[3] United Nations Programme on HIV/AIDS. AIDS epidemic update WHO, Geneva Switzerland; 2009.

[4] World Health Organization. Global HIV/AIDS response: Epidemic update and health sector progress towards universal access; 2011, WHO, Geneva Switzerland.

[5] Cunningham, A., Donaghy, H., Harman, A., Kim, M., Turville, S. Manipulation of dendritic cell function by viruses. Current opinion in Microbiology; 2010, 13(4): 524-529.

[6] Banerjee, U. Progress in diagnosis of opportunistic infection in HIV/AIDS. Indian Journal of Medical Resource; 2005,

[7] Jawetz, Melnick, and Adelberg. Opportunistic mycoses: In Medical Microbiology 23rd ed. Published by McGraw Hill Medical. chap; 2005, 45: 636-646.

[8] Topley and Wilson's. Microbiology and microbial infection. In Medical Mycology 10ed. Published by Hodder Arnold cha; 2005, 12: 293.

[9] Bharathi, M. and Usha- Rani A. Pathogenic fungal isolates in sputum of HIV positive patients. Journal of AIDS/HIV Research; 2011, 3(6): 107-113.

[10] Guidelines for prevention and treatment of opportunistic infections in HIV infected adolescents and adult. National institutes of Health, the center for disease control and prevention and the HIV medicine association of infectious disease society of America. MMWR; 2009, 58(4):98

[11] World Health Organization. Global tuberculosis. Control.http://www.who.int/tb/publications/globalreport/2 012/en/index.html.

[12] United Nations programme on HIV/AIDS. Chapter 2 epidemic update UNAIDS report on the global AIDS epidemic.www.unaids.org/documents/2010/1123GlobalRe port-chap2m.pdf. 
[13] Getahun, H., Gunneberg, C., Granich, R., Nunn, P. HIV infection associated with tuberculosis. Clinical Infectious Disease, 2010, 50(3): 201-207.

[14] Cheesbrough, M.Summary of the clinical and laboratory features of microrganisms. District Laboratory Practice in Tropical Countires, Part 2, 2nd edition. Cambridge University press, New York, USA; 2006, 178-298.

[15] McCantey M. Identification of fungi. In Practical Medical Microbiology. 14th edition Churchhill Livingstone London; 2008, 695-720.

[16] Karim, S.S., Churchyard G.J., Karim Q.A., Lawn S.D. Infection and Tuberculosis in South Africa. Lancet; 2009, 374(9693):921-933.

[17] Esebelahie, Newton O., Enweani, Ifeoma B., and Omoregie, Richard (2013). Candida colonization in asymptomatic HIV patients attending a tertiary hospital in Benin City, Nigeria. Libyan Journal of Medicine; 2013, 8(20322): 1-5.

[18] Esebelahie, N.O., Enweani, I.B., Omoregie, R. Candiduria among HIV-infected patients attending a tertiaryhospital in Benin City. African Journal of Clinical and Experimental Microbiology; 2014, 15(2):84-90.

[19] World Health Organization. Laboratory Manual for diagnosis of fungal opportunistic infections in HIV/AIDS patients. Chapter 2 Common opportunistic infections; 2009, 8-16.

[20] Ranajana, K.H., Priyokumar, K. and Singh, T.J. Disseminated Penicillummarneffei infection in HIV infected patients in Manipur State, India. Journal of Infectious Disease; 2002, 45(4):268-271.

[21] Bharathi, B., Sivasankar, S., and Swamidoss, D. (2010). Incidence of bacterial and fungal co-infection in some HIV infected Indian population. Indian Journal of Biotechnology; 2010, 3(2): 199-200. 